\title{
The Tower of Babylon - Bioreactor
}

\section{Khalidullin $\mathbf{O H}$}

Ecology Professor, Academician of the Russian Federation LAN, Kazakh National University, Russia.

Corresponding Author: Khalidullin OH, Ecology Professor, Academician of the Russian Federation LAN, Kazakh National University, Russia..

Received date: April 04, 2021; Accepted date: July 13, 2021; Published date: August 13, 2021

Citation: Khalidullin OH, (2021) The tower of Babylon - bioreactor. J, Biotechnology and Bioprocessing 2(6); DOI: 10.31579/2766-2314/037

Copyright: (C) 2021, Khalidullin OH, This is an open access article distributed under the Creative Commons Attribution License, which permits unrestricted use, distribution, and reproduction in any medium, provided the original work is properly cited.

\begin{abstract}
Biota - living organisms and plants, consuming oxygen, carbon and a lot of other substances, created and developed life and the very atmosphere of the planet. The main carrier of all chemical elements is water, which dissolves them from the soil, delivers them to the roots of plants, and is purified in bodies and plants and, by evaporation, rises into the atmosphere, where it takes part in creating precipitation. The quality of natural vapors, their volumes and speed have been created over millions of years in accordance with the need for biota. The water cycle has stabilized, providing a sufficient volume of water for a given area at aiven time.
\end{abstract}

Keywords: bioreactor; chemical elements; natural vapors

A man appeared and, with the development of civilization, the water cycle began to change. Human use of water in technological processes, irrigation of agricultural fields, transfer of heat and faeces in everincreasing volumes has led to a change in the quality of evaporation. The evaporation of water from a cup of tea or from asphalt is fundamentally different from the evaporation of biota. The volumes of evaporation new to nature - $10 \%$ of the flow of all rivers in the world - with new rates change into a different quality and have a different effect on the sedimentation process - the water cycle changes, and the climate changes from it: https://actascientific.com/ASMI/pdf /ASMI-04-0766.pdf

To stop climate change, we urgently need to return water to its natural functions.

There are many such directions. Some of them are:

- Refusal to build new and release existing reservoirs,

- Transition to drip irrigation and organic farming in crop production,

- Flood prevention,

- Improvement of plumbing with a complete revision of the concept of centralized sewerage,

- Cessation of deforestation and restoration of forest cover,

- Greening of buildings and structures,

- Transfer of urban infrastructures underground and under water,

- Reduction of the amount and volume of water consumption during washing all objects, such as cars and roads,
- Multiple use of water,

- Reduction of ore and waste landfills.

Each of these problems has its own difficulties, but it is necessary and quite solvable. Considering the last of these tasks, it is necessary to conduct a comprehensive analysis and create a cardinal solution. The expansion of areas for landfills for household waste reaches the limit there is a sorely lack of space around cities - some of them carry garbage for 40 - 70 kilometers or more. There are countries that export their waste. Every month about 10 ships call at the ports of Istanbul and Adana, carrying about 2000 tons of garbage: https://www.popmech.ru/science/492032-eksport-musora-iz-ssha-vbednye-strany-rassledovanie-the -guardian /.

Developed countries have established a variety of waste recycling and waste incineration systems. This is how landfills in Sweden disappeared, 32 categories of garbage are separated and recycled in Japan, and the ash of the burnt remains expands the area of the islands.

Other countries cannot come to a sufficient degree of recycling organization, do not have sorting and recycling technologies, and dump garbage in special places - landfills. With a height of more than 20 meters, landfills are dangerous with collapses. We have to fill up more and more new areas. In order to put as much garbage as possible per unit area, it is compacted with heavy equipment, which has its negative consequences. The decomposition of organic waste is accompanied by a rise in temperature and the release of gases, liquids, and fire. The environment is polluted.

"According to the World Bank Group https://www.ifc.org/wps/wcm/connect/news_ext_content/ifc_external_c 
orporate_site/news+and+events/news/cm-stories/serbia-waste-toenergy-ru, - annually in the world about 2 billion tons of municipal solid waste is generated and at least one third of them is not utilized in an environmentally sustainable manner. It is predicted that by 2050 this figure will grow to 3.4 billion tons. Landfills account for more than 3 percent of Europe's greenhouse gas emissions - and this figure is growing. " It does not take into account the artificial evaporation of drying precipitation from the entire area of the dumps and the destruction of the possibility of the formation of organic moisture from 20 tons of underground living creatures on each hectare below them. This is a fairly significant impact on the balance of the water cycle.

According to information: https://ecoportal.su/news/view/27413.html: an "Island" of garbage was formed in the Pacific Ocean and its area was twice the size of the United States.

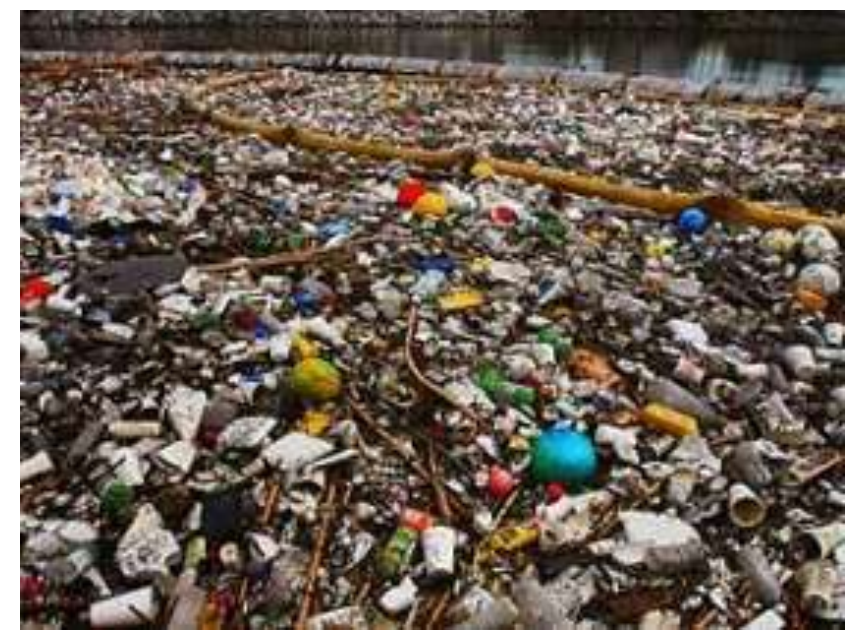

The total area of landfills on land was equal to that of Mexico and continues to grow. Raindrops wetting these "islands" and polygons evaporate unchanged. This is artificial evaporation - the water makes a useless, aimless idle run into the clouds and back, just like from asphalt, a plowed field, a cooling tower and drying clothes.

Garbage dumps are not natural products, in principle they should not exist. All substances are taken from nature for a while and must return to the soil and atmosphere. They must have their own circuit. The rubbish created by humanity will rot will burn up and enter the cycle. But very slowly and with the poisoning of the atmosphere, underground waters and habitats of living beings, of the person himself.

Everything created by humanity is a resource that is alien to nature. If we have created an object, then we are obliged to return to nature its component elements, to build them into the circulation of nature, maintaining the balance of the circulation of substances. So any object everything that is created by civilization, must turn into dust, like the human body itself.

But garbage and industrial waste cannot be buried separately, do not disappear by themselves, but are collected in landfills and landfills. Correctly seeing, understanding and dealing with the processes inside the garbage arrays will help to determine the actions for the early return to nature of all used chemical elements, without harm to humans.

Nature is not idle, but decomposes landfill waste into separate chemical elements into gases, liquids, compost. In the depths of the garbage, rotting, decomposition, aerobic and anaerobic composting, physical, chemical and biochemical conversions, and combustion occur. However, the productivity of the industry is growing much faster than nature can decompose.

We need to help Nature to do this without harming the environment. Compost is the most effective end product of decomposition, a means for increasing soil fertility, is a substance that is embedded in the cycle of substances. Percentage of waste types in household waste:

- $\quad$ Paper, cardboard 40.5

- $\quad$ Polymer materials 7.7

- $\quad$ Metals 2.0

- $\quad$ Glass 6.8

- Wood 9.5

- $\quad$ Textile, rubber, leather 1.8

- $\quad$ Food and organic waste, screening out 22.5

- $\quad$ Others 9.2.

Therefore, its main source or raw material for composting is food and vegetable waste, rags, paper. Everything else in humid conditions undergoes various reactions, and decreases in volume, for example, the metal rusts and turns into powder.

In Russia, there is not a single industrial enterprise that would carry out composting in large volumes and make it possible to clean at least one city from organic waste - http://ecology-of.ru/otkhody/problemyutilizatsii-tverdykh-bytovykh-otkhodov/.

A variety of composting methods are known: https://ruecology.info/page/00305647002705400740015000049256/:

Composting material (peat, soil) is placed on the site with a layer of 10 $15 \mathrm{~cm}$, then a layer of garbage up to $15 \mathrm{~cm}$ is laid, covered with a layer of composting material. Then a layer of garbage is added again, filled up, etc., until the height of the compost reaches $1.5 \mathrm{~m}$. The compost is covered with straw mats. Due to the vital activity of thermophilic microorganisms, biochemical processes take place in the compost and the garbage heats up to $50-70{ }^{\circ} \mathrm{C}$, organic matter is mineralized, and pathogenic microbes, helminth eggs and fly larvae die. The compost is shoveled every 1-2 months and periodically moistened. The ripening process lasts 3-12 months. Ripe compost is a loose, loose mass of dark earthy color. The 
advantages of composting include the fact that it does not pollute the environment, kill pathogenic microbes, and obtain valuable fertilizer.

However, the increased costly shoveling work does not allow handling large volumes of garbage, so the height of such piles and their volumes are limited.

Information method: https://news.solidwaste.ru/wpcontent/uploads/2019/02/Toropov_13_02.pdf

"CLIMATE CHAMBER" differs only in that it replaces tedding with a covering film and air supply.

There is no question of composting large volumes of garbage from the entire city. Therefore, the problem of reducing the growth of polygons is not solved in any way.

The main problem of waste disposal is the growth of waste storage areas at landfills. A sufficiently strong compaction of the landfill by the wheels of garbage trucks, bulldozers excludes the possibility of composting - due to the lack of oxygen, nitrogen, moisture. At the same time, the height of the polygon cannot exceed more than 70 meters.

Why not use the storage height, not 70, but 700 meters, 1000 meters. And do not squeeze the debris with equipment. Storage height - unused waste storage stock. The area of the base must be adequate in order to be stable.

In the last century, very high waste heaps were created. Mount Charlotte, located near the Polish town of Ridutlovy, is considered the highest in
Europe. The dump with a height of $135 \mathrm{~m}$ covers an area of 38 hectares.

Obviously, at that time, there were no such remarkable materials as strong, durable, and chemically resistant waterproofing materials, such as the GP geomembrane. If you use them, you can create tall enough towers filled with waste.

The proposed "Babylonian" tower according to the information: https://actascientific.com/ASMI/ASMI-04-0782.php solves the problem of recycling everything taken out of the city, garbage and will be able to recycle all the landfills surrounding the city. It is possible to load sludge from sewage sump, waste from various sawmills, processing and food enterprises. The essence of the technical solution lies in the fact that all garbage without preliminary sorting, except for harmful and radioactive elements, is placed in a single heap such as a waste heap without compaction. The upward feeding of material can be done with skip or mine hoists. We create a mine or a pipe, install a mine hoist in it, lift the debris inside the mine and dump it from above, without crushing or ramming. We get a tower of a very large truncated cone. The angle of the taper is approximately the angle of repose so as not to overload the walls. The area and height are hundreds of meters. Waste is not compacted, and water from above and air from below easily pass through the loose material. The temperature rises as it decomposes. Through the pipes left in advance.

There can be many design options. The simplest for illustration is the construction of a truncated cone in a geomembrane shell.



Figure 1

Figure 1 shows a diagram of household waste disposal. Garbage trucks dump garbage under a mine hoist, which lifts it up and pours it into a single heap at a given level. The outside of the pile is wrapped in a sheath of plastic materials. As the compost builds up and settles, it is scooped out by a scraper or similar device onto a sieve shaker. The finished compost is poured into one bunker, untreated and large foreign debris falls into another bin. As they fill up, trucks take these products to their destination.

The specific design may be somewhat different, but the point is that using the low fluidity of waste, it is possible to limit the spread of large volumes of waste by simple means.

Design calculations and experience can show the most advantageous design. A rigid frame may be required to support the shell. The frame of the structure and the frame of the walls and the central shaft can be made from piping systems. Water passes through the main system - a heat carrier. In another pipeline system, sensors are installed that indicate the temperature of the array. The third system provides air and water supply. 
A variant of cylinders, such as grain elevators, installed close to each other and forming a free space between themselves, where air will circulate, is possible.

During the decomposition of organic materials, moderately compressed only by the pressure of the upper layers, the process of composting and heating of organic and all adjoining nearby materials occurs. Water is pumped through the pipes, which, taking away heat, stabilizes the temperature regime of the composting process and prevents ignition and the formation of gases. The heat heats up nearby consumers, in particular, housing, swimming pools and cools the heating layers. The composting process continues under control and management. A decrease in the volume of garbage and the selection of compost at the very bottom leads to a gradual sliding of the entire mass downward, which causes tedding and mixing with water and air. Thus, a completely new engineering structure appears with almost no mechanical influences. The degree and layouts of pipes inside the waste masses are calculated according to experimental data. Water can be brought here from the sewer.

It is assumed that many other types of garbage, with prolonged exposure to a humid environment, turn into a loose dry substance. Everything that has not been completely processed is involved in the composting process and has its own structure and size at the exit. After passing through sieves and other types of sorting, everything inorganic and coarse can be easily separated and put into processing without manual labor. And small fractions can be launched in the second and third revolutions.

After a few months, in layers, the garbage rotts, slides down and turns into compost, the heat is used, there are no gases and other emissions.

The process is continuous as long as there is adequate emptying of the compost at the bottom and the supply of fresh waste at the top.

The proposal has a fairly high efficiency in waste disposal:

- In the process of complete decomposition, after a few months, the garbage turns into compost without odors and harmful substances, becomes fertilizer.
- Poisoning of the environment stops.

- The only sorting of waste can be after composting. Separation and extraction of "undigested" elements from loose and friable compost is easily mechanized and does not require manual sorting.

- Numerous sorting and recycling plants are not needed, labor and financial costs are reduced, areas of sorting and processing plants, collection containers with different types of waste.

- The area of many small landfills around cities is being significantly reduced.

- Nature is returning the degraded areas of liquidated landfills.

- Reduced surfaces of artificial vapors.

- There is a new infrastructure of the city - the possibility of creating recreation areas with the arrangement of observation areas, a ski slope, and greenhouses.

- Safety and harmlessness of processing will allow not to carry garbage far from the city.

The innovation is presented in an abbreviated form, it is necessary to carry out development work, experimentation, the creation of a new direction for waste processing and the return of natural vapors. Patenting is possible. I invite you to cooperation.

\section{Sources taken into account:}

1. http://optimum-

biodiversity.narod.ru/olderfiles/1/Bukvareva_Klimat.pdf

2. http://www.dslib.net/bio-fizika/vozdejstvie-bioty-na-globalnyjklimat.html

3. https://ecocrisis.wordpress.com/1-2/br-perspective/



This work is licensed under Creative Commons Attribution 4.0 License

To Submit Your Article Click Here: Submit Manuscript

DOI: $10.31579 / 2766-2314 / 037$

\author{
Ready to submit your research? Choose Auctores and benefit from: \\ * fast, convenient online submission \\ * rigorous peer review by experienced research in your field \\ * rapid publication on acceptance \\ * authors retain copyrights \\ * unique DOI for all articles \\ * immediate, unrestricted online access
}

At Auctores, research is always in progress.

Learn more https://auctoresonline.org/journals/biotechnology-andbioprocessing 